\title{
DEFICIÊNCIA AUDITIVA E ESCOLARIZAÇÃO: DESAFIOS PARA A PRÁTICA DOCENTE
}

\author{
Geórgia Barbosa Cardoso ${ }^{1}$
}

\section{RESUMO}

São inúmeros os desafios para a real inclusão de alunos nos espaços escolares, cabendo aos pesquisadores realizarem estudos em prol de soluções para esse problema. Assim, o presente estudo pretende fazer uma análise do processo de alfabetização e letramento das pessoas com deficiência auditiva, assim como da sua trajetória histórica e social rumo à inserção escolar. Dessa forma, realizou-se uma busca de referenciais teóricos que contribuíram para o aprimoramento das relações aluno-professor-família, com vistas a um processo efetivo de inclusão escolar desses alunos.

Palavras-chave: Deficiência Auditiva; Escolarização; Libras.

\begin{abstract}
There are numerous challenges for the real inclusion of students in school spaces, and it is up to researchers to conduct studies in favor of solutions to this problem. Thus, the present study intends to make an analysis of the literacy and literacy process of people with hearing impairment, as well as their historical and social trajectory towards school insertion. Thus, a search for theoretical references was carried out that contributed to the improvement of student-teacher-family relationships, with a view to an effective process of school inclusion of these students.
\end{abstract}

Keywords: Hearing Impairment; Schooling; Pounds.

\section{RESUMEN}

São inúmeros os desafios para a real inclusão de alunos nos espaços escolares, cabendo aos pesquisadores realizarem estudos em prol de soluções para esse problema. Assim, o presente estudo pretende fazer uma análise do processo de alfabetização e letramento das pessoas com deficiência auditiva, assim como da sua trajetória histórica e social rumo à inserção escolar. Dessa forma, realizou-se uma busca de referenciais teóricos que contribuíram para o aprimoramento das relações aluno-professor-família, com vistas a um processo efetivo de inclusão escolar desses alunos.

Palavras-chave: Deficiência Auditiva; Escolarização; Libras.

\footnotetext{
${ }^{1}$ Licenciada em Letras Português-Inglês e Pedagogia, especialista em Ludicidade e Psicopedagogia, Literatura e Ensino de Português e Docência para o Ensino Superior. E-mail: georgia.cardoso@yahoo.com.br
} 


\section{INTRODUÇÃO}

Os temas inclusão e educação especial nunca se fizeram tão presentes no ambiente escolar, na mídia, nos discursos políticos, nos documentos oficiais, portarias e leis. Encontra-se também uma vasta produção acadêmica acerca dos portadores de necessidades especiais, que historicamente sempre foram segregados da escola regular e dos processos educativos comuns. O presente trabaIho terá como enfoque principal o aluno com deficiência auditiva ou surdez, irá estudar e avaliar o seu processo de escolarização e os sistemas educacionais no qual está inserido, assim como analisar como se dá atualmente o seu processo de alfabetização e a atuação docente na promoção dessa aprendizagem.

Analisaremos, portanto, com base em estudos bibliográficos e pesquisa de campo: Como este aluno aprende? Faz ou não uso da Língua Brasileira de Sinais (LIBRAS)? Quais adequações curriculares e suportes the são oferecidos? Está ou não inserido na classe regular? Conta com um serviço de apoio e professores qualificados? Como se dá o seu processo de alfabetização e letramento? Como é avaliado?

Na seção Deficiente auditivo: da situação irregular a garantia de direitos, analisaremos do ponto de vista histórico e cultural, a trajetória das pessoas com deficiência. Estudaremos mais especificamente fatores relacionados às pessoas com deficiência auditiva no Brasil, assim como as leis e documentos oficiais que tratam desse assunto.

Assim, na sequência, o leitor irá encontrar Etiologia e prognóstico da deficiência auditivo, com uma análise detalhada das causas e formas de tratamento existentes na atualidade no que se refere à deficiência auditiva.

A seguir, O processo de escolarização do deficiente auditivo destacará a importância do conhecimento das especificidades da escolarização do deficiente auditivo, além da descrição dos suportes e estratégias para que possa alcançar a alfabetização e o letramento. Finalizando o estudo, apresento as Considerações Finais, que contém as reflexões teóricas, provenientes desses dados bibliográficos. 
DEFICIÊNCIA AUDITIVA: DA SITUAÇÃO IRREGULAR À GARANTIA DE DIREITOS

A história da humanidade nos mostra que, desde os tempos remotos, os deficientes eram mantidos à margem dos acontecimentos sociais, não apenas por limitações intrínsecas à sua própria condição, mas também por limitações imputadas por uma sociedade que levava o indivíduo a uma situação de descrédito. Acreditava-se que todos os indivíduos que suscitassem a repulsão ou temor, considerados como ameaças à sociedade deviam ser afastados e confinados num espaço isolado do convívio social.

As prostitutas, os indigentes, os incapazes e os deficientes eram recoIhidos, para que fossem cuidados, mas, na verdade, o que se praticava era o seu isolamento e exclusão, para proteger a sociedade da desordem dos loucos, dos diferentes e dos perigos que eles representavam. (OLIVEIRA, 2011, p.36).

Ainda de acordo com Oliveira (2008), durante muito tempo, o indivíduo deficiente ficou totalmente à margem da sociedade, não sendo permitido a ele o convívio e a participação ativa e plena junto ao grupo social. Esse comportamento ocorreu por décadas, de geração para geração, sem reflexão e com base em conceitos hoje considerados ultrapassados acerca do deficiente e da deficiência.

$\mathrm{Na}$ Antiguidade, as relações econômicas (agricultura, pecuária, artesanato) serviam de parâmetro para a sociedade, formada, então, por nobres e não nobres. Pessoas diferentes (deficientes, doentes, idosos), ou seja, os que não podiam exercer atividades que gerassem renda eram praticamente exterminados por meio do abandono. Os deficientes não eram considerados "humanos", atitude da sociedade em relação a eles é de intolerância e punição, representada por ações de aprisionamento, tortura, açoites e castigos severos. Em Roma e na Grécia, os surdos eram considerados "enfeitiçados" e eram lançados ao abandono ou a morte. Já no Egito, eram adorados e vistos como "enviados dos deuses", acreditavam que os surdos se comunicam sem segredo com eles.

Na Idade Média, com o advento do Cristianismo, temos uma nova concepção de homem, a de um ser racional, criação e manifestação de Deus. A deficiência humana é atribuída ao castigo divino, que é categoricamente atribuída ao 
demônio. Segundo Oliveira (2008) até a expansão do Cristianismo pela Europa, a deficiência não constituía um problema, porque a sociedade simplesmente os ignorava, tendo como prática o abandono dos que apresentavam alguma anormalidade, o que não era até então considerado uma violação moral na ética moral vigente. No entanto, as ideias cristãs preconizam aos deficientes o status humano, ou seja, eles possuíam alma e não podiam mais ser exterminados. Para sobreviver, dependiam da boa vontade e da caridade humana. Não era permitido aos surdos, entretanto, receber comunhão por não poderem confessar os seus pecados. Também não Ihes era possível casar, nem receber herança.

No século XVI, com o início da Revolução Burguesa, acontece uma revolução de ideias, destruíram-se as monarquias e a hegemonia da Igreja Católica. É implantada uma nova forma de produção: o capitalismo mercantil. Com o capitalismo, os deficientes são considerados indivíduos não produtivos que oneravam a sociedade no que se refere ao seu sustento e manutenção. A deficiência ainda não era vista como algo que mereça atenção.

Ainda nessa época, de acordo com Souza (2012, p.34), surge na Europa a primeira escola para surdos. Na Espanha, o monge beneditino Pedro Ponce de Leon (1510-1584) ensinava latim, grego, italiano, física e astronomia a dois irmãos surdos membros de uma importante família de aristocratas. Para isso, ele utilizava a datilografia, a escrita e a oralização. Um dos irmãos conquistou o direito à herança e o outro conseguiu se tornar padre. Porém, após a morte de Leon, o método caiu no esquecimento, pois ele não havia publicado nada a respeito do seu trabalho.

No século XVII, começa a se formar uma visão médica de deficiência, com o paradigma da institucionalização. Para Rizzini (2008), no Brasil e em outros países do mundo, essas ações tinham para o Estado, uma proposta de civilização "saneadora". Neste sentido, a ideia era sanear a sociedade, através de instituições filantrópicas de cunho social, na sua maioria, dirigida por instituições religiosas que impunham um discurso de moralidade que enquadrassem nas massas, deixando de lado a contenção apenas pela fé, para a regulação de comportamentos pela moral. Todos os que se encontravam em situação não considerada normal para o padrão social da época eram enquadrados nesse paradigma: órfãos, promíscuos, deficientes ou loucos. 
O termo sanear, extraído da medicina, era com frequência empregado no discurso sobre a transformação do país, para designar a necessidade de curar ou remediar os males, que ali grassavam. Denotava particular interesse nos males de cunho moral, associadas às pessoas tidas como inferiores (RIZZINI, 2008, p. 107).

Em 1620, Jean-Paul Bonet funda a primeira "instituição" especializada para educação de "surdos-mudos". No mesmo período, na França, de acordo com Sacks (1989), o Abade Michel de L'Epée inventou o método de "Sinais Metódicos", considerada como a primeira língua de sinais oficial. O método era uma combinação de sinais com a gramática francesa e era aplicado em uma escola dedicada a crianças surdas. Em 1791, devido ao sucesso alcançado, ela se transforma no Instituto Nacional de Surdos e Mudos de Paris. Com influência da língua de sinais francesa, os Estados Unidos utilizam a ASL (Língua de Sinais Americana) para a educação de surdos.

No Brasil, em 1855, chegou aqui o professor surdo francês Hernest Huet, trazido pelo imperador D. Pedro II, para iniciar um trabalho de educação de duas crianças surdas, com bolsas de estudo pagas pelo governo. Em 26 de setembro de 1857, é fundado o Instituto Nacional de Surdos-Mudos, atual Instituto Nacional de Educação de Surdos (INES), que utilizava a língua de sinais (GOLDFELD, 2002, p. 32).

Skliar (1997) afirma que, em 1880, acontece o "Congresso de Milão", com o objetivo de nortear a educação dos surdos. Seus participantes provinham de vários países e eram na sua maioria ouvintes. Foi decidido, nesse congresso, que o oralismo, era o método mais acertado que a prática de gestos e sinais. Para eles, o surdo ao utilizar gestos, não teria interesse em falar e, portanto, essa prática deveria ser abolida.

O autor ainda ressalta outro fato importante decorrente do período pós Congresso de Milão, a surdez e consequentemente a mudez, adquiriu status de doença, de deficiência e passou a ser tratada mais pelo enfoque médico, do que pelo educacional. As escolas passaram a agir como salas de tratamento, proibindo terminantemente o uso de sinais, com repreensão, castigos físicos (há relatos de que amarravam as mãos dos alunos), e exercícios repetitivos e cansativos de oralização, com vistas a corrigir os defeitos da fala e o aprimoramento da leitura labial. 
(..) no célebre Congresso Internacional de Educadores de Surdos, realizado em 1880 em Milão, no qual os próprios professores surdos foram excluídos da votação, o oralismo saiu vencedor e o uso da língua de sinais nas escolas foi "oficialmente abolido". Os alunos surdos foram proibidos de usar a sua própria língua "natural" e, dali por diante, forçados a aprender, o melhor que pudessem, a (para eles) "artificial" língua falada. (SACKS, 1998, p.40).

Goldfeld (2002) aponta que em 1911, no Brasil, o INES, seguindo a tendência mundial estabeleceu o Oralismo puro em todas as disciplinas, sendo terminantemente proibida a língua de sinais, embora continuasse sendo utilizada pelos alunos nos pátios e corredores da escola.

Oliveira (2008) afirma que se defendia a normatização da pessoa com deficiência, ou seja, a incluía na sociedade com a finalidade de que ela possa adquirir condições e padrões de vida cotidiana o mais próximo do normal. Ele tinha que se adaptar às exigências do meio, o contrário não acontecia, a sociedade em momento algum necessitava realizar mudanças e adequações para incluí-lo. No que se refere aos surdos, eles deviam ser oralizados, "normatizados" às demais pessoas.

De acordo com Poker (2008), somente na década de 1960, é que se começa a pensar novamente na educação dos surdos, tendo em vista estudos que apontavam o fracasso do Oralismo. Ponto reafirmado por Sacks (1998, p. 42) “E foi só na década de 1960 que historiadores e psicólogos, bem como pais e professores de crianças surdas, começaram a indagar: "O que aconteceu? O que está acontecendo?"

A pretensa resolução do problema foi a criação de um sistema "combinado", que somasse sinais e fala. Nos Estados Unidos, surge a "Comunicação Total", método inserido pelo professor Roy Rolcomb. Nessa abordagem, a língua de sinais e o oralismo coexistem. Apesar de trazer avanços em permitir o uso de sinais, confundia o aluno com surdez, pois trabalhar com sinais e oralização ao mesmo tempo, correspondia a ter que aprender e falar duas línguas simultaneamente.

Na década de 1990, principalmente a partir da Declaração de Salamanca ${ }^{2}$ em 1994 surge o "paradigma de suporte" que se estende até os dias atuais.

2 Esta Estrutura de Ação em Educação Especial foi adotada pela conferência Mundial em Edu-
cação Especial organizada pelo governo da Espanha em cooperação com a UNESCO, realizada
em Salamanca entre 7 e 10 de junho de 1994 . Seu objetivo é informar sobre políticas e guias
ações governamentais, de organizações internacionais ou agências nacionais de auxílio, 
Nessa concepção, a relação da pessoa com deficiência com a sociedade, se dá de forma dual. O indivíduo é levado a se adaptar ao meio social, mas em contrapartida a sociedade também tem que se adequar a ele (escola inclusiva, acessibilidade urbana, comunicação assistiva - LIBRAS e Braille, assistência social, entre outros). Portanto, na abordagem centrada na pessoa deficiente considerase que os fatores orgânicos, como lesões e malformações, congênitas ou adquiridas, se constituem em causas primárias da deficiência.

$\mathrm{Na}$ abordagem centrada no meio, os fatores ambientais, como a miséria e pobreza, estimulação e tratamento inadequados, e outras condições desfavoráveis para o desenvolvimento normal, são tratados como sendo causas primárias das deficiências. $O$ olhar para a deficiência deve sempre levar em conta o indivíduo e suas limitações e o meio no qual está inserido.

\begin{abstract}
Esse novo olhar precisa ser acompanhado com muita atenção. A preocupação excessiva em tirar o foco de atenção, que recaia sobre o deficiente, pode conduzir-nos ao erro de procurar intervir apenas no meio, entendendo que somente ele deve ser modificado e adaptado, para poder acolher as pessoas com toda e qualquer diferença. Por outro lado, é imprescindível também o empenho no sentido de cada uma das pessoas, equacionando convenientemente as diferenças que possam apresentar, seja capacitada para adequar-se às demandas do meio (OMOTE, 2011 apud OLIVEIRA, 2008, p. 22).
\end{abstract}

Dentro dessa nova abordagem, em relação à educação dos surdos, surge o Bilinguismo. O surdo nessa abordagem deve ser bilíngue, ou seja, adquirir sua língua natural (no Brasil, a LIBRAS - Língua Brasileira de Sinais) e uma segunda língua pertencente a comunidade ouvinte na qual está inserido (no nosso caso a Língua Portuguesa). Consideram que o surdo cria uma nova forma de comunicação, com uma cultura e língua própria. A criança deve aprender LIBRAS com um adulto surdo. Com bases teóricas em Vygotsky e Chomsky, acreditam que a criança que não é exposta a língua de sinais terá problemas cognitivos, emocionais e sociais. Essa abordagem vem ocupando grande espaço mundial (EUA, Canadá, Suécia, Venezuela etc).

A questão principal tratada pelo bilinguismo é a preocupação em entender o surdo, suas particularidades, sua língua (a língua de sinais), sua cultura e a

organizações não governamentais e outras instituições na implementação da Declaração de Salamanca sobre princípios, Política e prática em Educação Especial (DECLARAÇÃO DE SALAMANCA, 1994, p.4). 


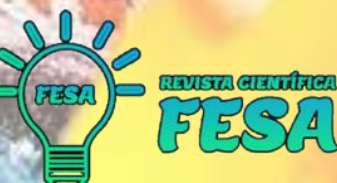

forma singular de pensar e agir, deixando de lado apenas os aspectos biológicos da surdez.

Outro fator importante apontado por Poker (2008) é que o bilinguismo trouxe foi a diferenciação entre os termos "surdez" e "deficiência auditiva". O surdo não se considera com "deficiência", mas sim um ser humano que se comunica de forma gesto visual e não quer de forma alguma se oralizar ou ouvir. O deficiente auditivo usa meios para se oralizar e ouvir (aparelhos auditivos, implantes cocleares) e não se considera surdo.

[...] começa a surgir uma nova visão em relação ao surdo e à língua de sinais. Percebe-se a necessidade de valorizar esta língua e sua cultura, e não a misturar com a língua oral. A língua de sinais, seus valores e sua cultura passam a receber a atenção de diversos profissionais de diferentes áreas. Surge então uma nova filosofia educacional para surdos, em que o bilinguismo apresenta-se como base de ensino e aprendizagem (GOLDFELD, 2002, p.14).

Note que não é uma diferença por grau de perda auditiva, mas de ideologia e ações próprias de cada indivíduo, e que os estudiosos chamam de "cultura surda". Para os bilinguistas, de acordo com Goldfeld (2002), o surdo não precisa almejar uma vida semelhante ao ouvinte, podendo aceitar e assumir sua surdez.

\section{O DEFICIENTE AUDITIVO RELATADO NAS LEIS E DOCUMENTOS OFICIAIS}

A escolarização do aluno com deficiência tem sido um tema bastante debatido em educação especial, inclusive em relação à modalidade de atendimento que seria melhor para esse aluno. Historicamente, o acesso desses alunos à educação vem sendo assegurado através de leis educacionais, desde a Lei 4.024/61, que preconizava os direitos dos "excepcionais" à educação, já, naquele momento, trazendo como princípio que "no que for possível, enquadra-se no sistema geral de educação, a fim de integrá-los na comunidade" (BRASIL, 1961, p.33).

As leis 5.692/71 e a lei 7.044/82, ao fixarem as diretrizes básicas do ensino de $1^{\circ}$ e $2^{\circ}$ graus, também tratam da escolarização dos alunos com deficiência, preconizando "tratamento especial aos alunos que apresentam deficiências físicas ou mentais" (MAZZOTTA, 1986, p.68).

No que se refere especificamente aos direitos dos deficientes auditivos/surdos, temos primeiramente a Resolução CNE/CEB n 르 2, de 11 de setembro de 
2001, que institui Diretrizes Nacionais para a Educação Especial na Educação

Básica, e que em seu Artigo 5, capítulo Il considera:

[...] Art. 5을 Consideram-se educandos com necessidades educacionais especiais os que, durante o processo educacional, apresentarem: II dificuldades de comunicação e sinalização diferenciadas dos demais alunos, demandando a utilização de linguagens e códigos aplicáveis. [...] Art. $8^{\circ}$ As escolas da rede regular de ensino devem prever e prover na organização de suas classes comuns: IV - serviços de apoio pedagógico especializado, realizado, nas classes comuns, mediante: a) atuação colaborativa de professor especializado em educação especial; b) atuação de professores-intérpretes das linguagens e códigos aplicáveis (BRASIL, 2001)

Em 24 de abril de 2002, a Lei Federal 10.436, dispõe sobre a Língua Brasileira de Sinais (LIBRAS), determinando o seu reconhecimento como meio legal de comunicação e expressão, oriundo de comunidades de pessoas surdas no Brasil, não podendo, no entanto, substituir a modalidade escrita da língua portuguesa, assegura no seu Art. $4^{\circ}$ que:

O sistema educacional federal e os sistemas educacionais estaduais, municipais e do Distrito Federal devem garantir a inclusão nos cursos de formação de Educação Especial, de Fonoaudiologia e de Magistério, em seus níveis médio e superior, do ensino da Língua Brasileira de Sinais - Libras, como parte integrante dos Parâmetros Curriculares $\mathrm{Na}$ cionais - PCNs, conforme legislação vigente (BRASIL, 2002).

\section{O decreto 5.626 de 22 de dezembro de 2005, regulamenta a Lei Federal}

10.436, acima citada e dá outras providências, entre elas:

CAPÍTULO I Art. 2o Para os fins deste Decreto, considera-se pessoa surda aquela que, por ter perda auditiva, compreende e interage com o mundo por meio de experiências visuais, manifestando sua cultura principalmente pelo uso da Língua Brasileira de Sinais - Libras [...] CAPÍTULO IV Art. 16. A modalidade oral da Língua Portuguesa, na educação básica, deve ser ofertada aos alunos surdos ou com deficiência auditiva, preferencialmente em turno distinto ao da escolarização, por meio de ações integradas entre as áreas da saúde e da educação, resguardado o direito de opção da família ou do próprio aluno por essa modalidade. [...]

Art. 22. As instituições federais de ensino responsáveis pela educação básica devem garantir a inclusão de alunos surdos ou com deficiência auditiva, por meio da organização de: I - escolas e classes de educação bilíngüe, abertas a alunos surdos e ouvintes, com professores bilíngües, na educação infantil e nos anos iniciais do ensino fundamental; II - escolas bilíngües ou escolas comuns da rede regular de ensino, abertas a alunos surdos e ouvintes, para os anos finais do ensino fundamental, ensino médio ou educação profissional, com docentes das diferentes áreas do conhecimento, cientes da singularidade 


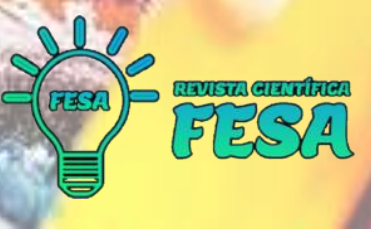

lingüística dos alunos surdos, bem como com a presença de tradutores e intérpretes de Libras - Língua Portuguesa [...] (BRASIL, 2005).

No Munícipio de São Paulo, a portaria № 5.707 de 13 de dezembro de 2011, institui as EMEBs (Escolas Municipais de Educação Bilingue para Surdos), assegura no seu Art. $2^{\circ}$ :

A educação de alunos surdos em unidades educacionais da rede municipal de ensino deve reconhecer o direito dos surdos a uma educação bilíngüe que respeite sua identidade e cultura, na qual a Libras é a primeira Língua e, portanto, língua de instrução e a Língua Portuguesa é a segunda, sendo objeto de ensino da escola a modalidade escrita. (SÃO PAULO, 2011).

\section{O PROCESSO DE ESCOLARIZAÇÃO DA PESSOA COM DEFICIÊNCIA AU- DITIVA}

No Brasil, de acordo com o Censo Demográfico $(2000)^{3}$, existe um total de 766.344 crianças e jovens surdos, com idade entre 0 e 24 anos, deste total apenas 56.024 frequentam a escola.

Poker (2008) afirma que surdez é a perda da capacidade total ou parcial de ouvir. É medida em dB (decibéis), uma unidade de medida da intensidade dos sons. Uma pessoa com a audição normal, apresentará a medição de até $20 \mathrm{~dB}$. Acima de $25 \mathrm{~dB}$ (perda leve) - já é considera surda; de 25 a $40 \mathrm{~dB}$ (moderada); de 40 a $70 \mathrm{~dB}$ (moderada/severa), de 70 a $90 \mathrm{~dB}$ (severa) e acima de $91 \mathrm{~dB}$ (profunda). As causas podem ser de origem genéticas, sindrômicas, provocada por doenças (citomegalovírus, herpes, rubéola, sífilis, toxoplasmose, varicela), e ainda ambientais (síndrome alcoólica fetal, traumas, envenenamento, desnutrição).

Dois dispositivos podem ser usados, dependendo do grau de perda auditiva, para a mediação auditiva: os aparelhos auditivos e os implantes cocleares.

Aparelhos auditivos são dispositivos eletrônicos que amplificam as ondas sonoras, levando uma pessoa com perda auditiva a ouvir os sons. Os aparelhos auditivos amplificam as células ciliares que ainda funcionam, estimulando-as. É muito difícil, mesmo nos casos de surdez severa, não ter pelo menos algumas células funcionando (POKER, 2008).

${ }^{3}$ Fonte: http://www.feneis.com.br/page/quantitativo.asp Acesso em: 25 jun. 2021. 
O implante coclear é inserido através de cirurgia no cérebro e substitui todo o complexo auditivo, levando os estímulos elétricos diretamente ao cérebro. Esse procedimento deve ser realizado preferencialmente até os 03 anos de idade (idade na qual ainda o cérebro está em formação). Mesmo assim, os implantados ouvem de maneira mecanizada, meio robótica, tendendo a falar também dessa maneira.

O implante coclear é um aparelho eletrônico que funciona como uma prótese auditiva, na medida que desempenha a função das células ciliares ao fornecer a estimulação elétrica às células ganglionares espirais remanescentes no nervo auditivo da cóclea (CAPOVILLA, 1988, p.75).

O acesso gratuito a esses aparelhos é garantido pelo Decreto ํㅜ 3.298 de 20 de dezembro de 1999, e oferecido pelo SUS (Sistema Único de Saúde). São considerados ajudas técnicas na superação da deficiência auditiva. Até os 2 anos de idade, tanto o surdo como o ouvinte se equiparam no desenvolvimento, pois nessa fase a linguagem ainda não é fator primordial. A partir daí acontece a disparidade (POKER, 2008). Prejuízos na função simbólica acarretam problemas na linguagem oral e consequentemente na cognição.

O desenvolvimento mental se dá em três fases: sensório motor (universo prático), representação (linguagem) e o período operatório (universo conceitual). O surdo não tem a função simbólica, pois possui apenas a função concreta, o universo prático do objeto. Para passar para a fase da representação necessita da linguagem, pois sem ela não passará para o período da formação de conceitos. Por exemplo: ele não tem a função simbólica de tempo (não sabe o que é amanhã, hoje, ontem), pois esses conceitos não são transmitidos de forma concreta, visual, prática. São conceitos aprendidos de forma figurativa e cultural, mediados pela linguagem.

Vygotsky (1999) considera que a linguagem é um signo mediador fundamental, para a constituição das funções psicológicas superiores. A fala que é uma característica social e externa, que quando internalizada dá origem ao pensamento. Portanto, a principal consequência da surdez é a falta de linguagem. Sem ela o pensamento não se torna social, ou seja, o sujeito não consegue expor o que pensa. Há prejuízos em ações de troca de experiências, na compreensão e explicação dos fatos. O sujeito fica preso ao imediato e têm como consequência final o "atraso cognitivo", por não conseguir expor pensamentos mais 
complexos. É comum por esse motivo, ver surdos adultos infantilizados. Para esse autor, o aprendizado escolar é um momento determinante para o desenvolvimento da criança, "e é também uma poderosa força que direciona o desenvolvimento, determinando o destino de todo o seu desenvolvimento mental" (VYGOTSKY, 1999, p.107).

Goldfeld (2002) também aponta que a dificuldade ao acesso de uma língua que seja oferecida natural e constantemente leva a criança surda a um tipo de pensamento mais concreto, já que é pelo diálogo e aquisição do sistema conceitual que ela pode desvincular-se cada vez mais do concreto, internalizando conceitos abstratos.

A falta da linguagem como orientadora do pensamento, passa a falsa impressão de que o surdo é intelectualmente incapaz. Daí a importância da aprendizagem escolar, ela irá exigir da criança o controle das principais funções psicológicas superiores que ainda estão em desenvolvimento, a atuação pedagógica deverá, intencionalmente, direcionar esse processo, uma vez que "o único tipo positivo de aprendizado é aquele que caminha à frente do desenvolvimento, servindo-lhe de guia" (VYGOTSKY, 1999, p.130). Além disso, as reclamações mais frequentes referentes ao aluno surdo é de que ele é ansioso, nervoso, agressivo. Isso se deve geralmente por ele não entender o que está acontecendo em sua volta, e, também, não se fazer entendido. "A inclusão de alunos com surdez nas classes regulares de ensino se constitui em um grande desafio, em decorrência da diferença linguística que Ihes é peculiar" (POKER, 2008, p.177).

Ainda neste sentido, Goldfeld (2002, p. 74) considera que "a aprendizagem está associada ao lugar social que a criança ocupa, as expectativas que os adultos criam a seu respeito. A aprendizagem que se inicia pelas relações interpessoais, necessita, na maioria das vezes, da linguagem." Mais uma, então, entendemos o problema do surdo que segue caminhos diferentes dos das crianças que passam por um processo de aprendizagem formal, escolar, sem dificuldades linguísticas.

Mas, qual a melhor forma de resolver essas questões? Existem três abordagens de ensino de linguagem, para alunos com deficiência auditiva/surdez, como já citado anteriormente: Oralismo, Comunicação Total e Bilinguismo.

Podemos perceber que em qualquer uma das abordagens, fica claro que 0 apoio da linguagem (LIBRAS ou oral) é fundamental. 
[...] a questão de comunicação para a criança surda tem sido ponto de controvérsia entre profissionais e pesquisadores, que se acham divididos em oralistas, que acreditam que independente do grau de déficit auditivo o surdo deve ser levado a falar e a desenvolver competência linguística oral e assim ser integrado ao mundo dos ouvintes e os bilinguístas que enfatizam a importância da comunicação seja ela oral ou não (PETEAN e BORGES, 2012, p.196).

Existem também três propostas de alternativas de inclusão escolar de alunos com deficiência auditiva/surdez, os chamados AEE (Atendimento Educacional Especializado): 1) escola comum em classe regular, com atendimento educacional especializado em período contrário - contraturno; 2) escola comum com classe especial 3) Escola Especial - apenas com alunos deficientes auditivos/surdos.

No Brasil, atualmente o MEC (Ministério da Educação e Cultura) defende o bilinguismo e o período de horas diárias (contraturno) para o AEE (Atendimento Educacional Especializado), como já citado no capítulo anterior.

O uso da LIBRAS (Língua Brasileira de Sinais) tem papel primordial, e sua importância na educação de deficientes auditivos/surdos, item ressaltado por diversos autores.

O caráter de uma língua é essencialmente cultural [...] - expressa e
determina o modo como todo um povo pensa e aspira. No caso da
língua de sinais, aquilo que a distingue, seu "caráter", é também bioló-
gico, pois se alicerça nos gestos, na iconicidade [...] A língua de sinais
é para os surdos uma adaptação única a um outro modo sensorial; mas
também, e igualmente, uma corporificação da identidade pessoal e cul-
tural dessas pessoas [...] (SACKS, 1998, p.136).

"A língua de sinais seria a única língua que o surdo poderia dominar plenamente e que serviria para todas as suas necessidades de comunicação e cognitivas" (GOLDFELD, 2002, p.45). Além disso, Fernando Capovilla (2006), atualmente chefe do laboratório de Neuropsicolinguística Cognitiva Experimental da USP, e autor em 2004 do primeiro dicionário, atribui como principal dificuldade do processo de escolarização dos alunos com deficiência auditiva, o fato de que professores ouvintes e alunos surdos se comunicam em línguas diferentes, português para os primeiros e Libras para os segundos.

Poker (2002) descreve alguns erros frequentes dos professores de alunos com deficiência auditiva/surdez: simplificar e reduzir frases; omitir informações complexas; restringir-se a dados concretos; evitar situações de conflito cognitivo; não estimular a argumentação, a troca de ideias; fazer de conta que está 


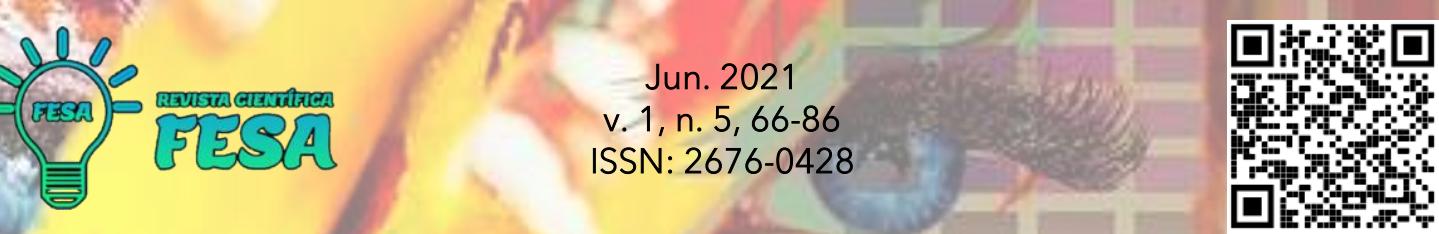

entendendo o que o aluno está falando. Ações práticas que podem proporcionar um melhor processo de ensino e aprendizagem desse aluno: aulas mais visuais, antecipar o que vai acontecer (com figuras ou demonstrando o horário em que vai acontecer a atividade), organizar a sala no sentido de que ele possa visualizar os colegas também, falar olhando para eles e a diminuição de aulas totalmente expositivas.

\section{DEFICIÊNCIA AUDITIVA NA PRÁTICA}

Participaram voluntariamente deste estudo cinco professores, que atuam em escolas de ensino fundamental da cidade de São Paulo, e que têm alunos com deficiência auditiva/surdez.

O instrumento para a coleta de dados foi um questionário com questões fechadas (Anexo 1). As perguntas versaram sobre como ocorre o processo de escolarização e relações família-escola do aluno com deficiência auditiva/surdez no local de trabalho do professor entrevistado.

A coleta de dados junto aos pesquisados foi feita em uma única sessão de coleta de dados, mediante aplicação de questionário impresso autoexplicativo, com a presença do pesquisador.

Como resultado da pesquisa há dados indicativos de que $100 \%$ dos pais, têm medo de que seus filhos sofram discriminação na escola. Em contrapartida, os professores entrevistados afirmaram que não perceberam em nenhum momento qualquer discriminação ou rejeição sofrida por esses alunos. Esses dados, afirmam o exposto por Glat (1996) que, mesmo ultrapassado o luto e o choque inicial da descoberta da deficiência, esse sofrimento psicológico poderá voltar a acontecer em momentos chaves da vida da criança, como por exemplo, no momento de entrar para a escola.

Para servir de base na análise das famílias foi questionado: Qual o sentimento percebido na família em relação ao aluno com deficiência auditiva? Se necessário cite mais de um. As alternativas foram: amor, tristeza, medo, decepção, angústia, culpa, impotência, ansiedade, raiva, revolta, dúvida, superproteção, vergonha e outros.

A totalidade dos professores inquiridos (cinco) responderam que as famílias são amorosas. Quatro afirmaram que além de amor, os pais são superprotetores 


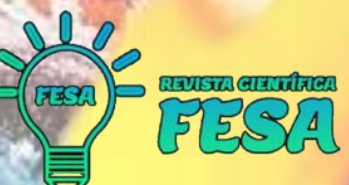

e sentem vergonha da deficiência do filho. Ainda quatro professores apontaram que os pais têm dúvida em relação ao futuro dos filhos.

Oliveira (2008) ressalta que os pais precisam elaborar a perda do filho idealizado que se tornou real e a frustração narcísica de colocar no mundo um filho com deficiência.

Os pais do deficiente também sentem vergonha, sentimento esse mais centrado nos outros, no que a sociedade vai pensar a respeito do seu filho. Quando os indivíduos se tornam pais, veem os filhos como uma extensão de si mesmos. Esperam que as crianças, de certa forma, se tornem um reflexo do melhor de si próprios e sentem-se envergonhados quando isso não acontece (BUSCAGLIA, 2006, p. 107).

A reprodução no seio familiar e nas relações de amizade, de estigmas relacionados à deficiência, é mais um empecilho à sua aceitação. A ideia de que serão eternamente dependentes e discriminados socialmente, criam uma imagem negativa que geralmente é internalizada pela criança. Outro sentimento normalmente presente nas famílias de pessoas com deficiência é a superproteção, que conduz a uma condição de dependência e falta de autonomia, na medida em que os pais privam a criança de realizar diversas ações de vida diária, fazendo tudo por elas, comprometendo bastante o seu desenvolvimento e provocando ainda uma eterna infantilização do deficiente intelectual.

Sawrey e Telford (1978) observam padrões de dependência mútua entre pais e filhos com deficiência. A criança devido ao exagero de cuidados dos pais torna-se extremamente dependente. Em contrapartida os pais, mais frequentemente a mãe, torna-se dependente dessa criança, toda a sua vida fica concentrada nela, querem mostrar-se bons pais e indispensáveis a sua sobrevivência.

Quando solicitado os pais dos alunos comparecem à escola, ainda que não prontamente. Todos os professores participantes consideram também que a participação da família influi positivamente no processo de ensino e aprendizagem.

A totalidade dos inquiridos afirmou que os alunos fazem tratamento médico periódico e frequentam outras instituições além da escola. Todos os alunos frequentam a sala regular de ensino, e no contraturno $o$ atendimento educacional especializado (AEE).

Em relação aos suportes e ajudas técnicas próprios para a deficiência auditiva, surdez, todos os cinco alunos fazem uso de Libras. Três alunos utilizam 


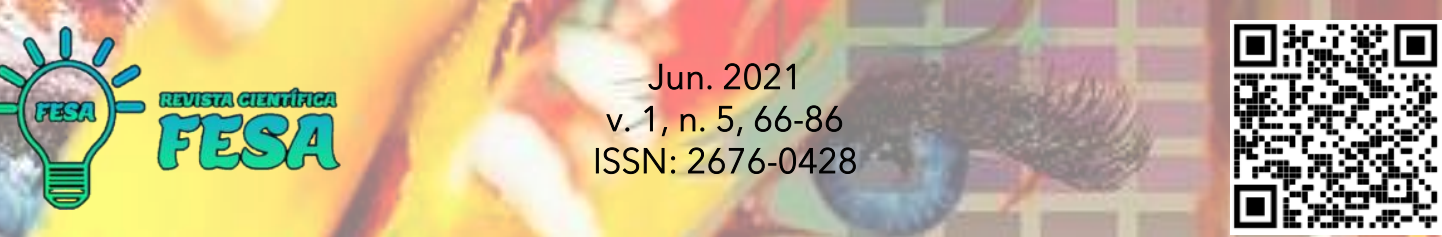

aparelhos auditivos, dois se comunicam em Libras e também de forma oral, e outros dois fazem uso de Libras e de outros gestos e sinais.

No que diz respeito à formação dos professores, três entrevistados não tinham nenhuma especialização na área e dois tinham especialização em deficiência auditiva. Apenas dois professores dos cinco entrevistados contavam com o auxílio de um intérprete de Libras.

A totalidade dos entrevistados afirmou fazer adaptação curricular. A avaliação dos alunos é realizada apenas algumas vezes de forma diferenciada. Neste sentido, de acordo com a LDB (Lei de Diretrizes e Bases da Educação), os currículos do ensino fundamental, devem ter uma base nacional comum, complementada por uma base diversificada, a critério dos estabelecimentos de ensino e exigida "pelas características regionais e locais da sociedade, da cultura, da economia e da clientela" (BRASIL, 1997, p.19). Assim, do ponto de vista legal e da organização curricular, há garantia de flexibilização, adequação e diversificação curricular para atender os alunos com deficiência.

Apenas na sala de três professores dos cinco inquiridos, o número de alunos é reduzido, com vistas a aprimorar o processo de ensino e atenção para com o aluno com deficiência auditiva.

Os professores relataram na pesquisa, quais as principais dificuldades enfrentadas por eles, para alcançar a escolarização do aluno com deficiência auditiva/surdez. Dos cinco professores, dois apontaram como principal dificuldade, o fato de não ter domínio e conhecimento de Libras, o que dificulta a interação e a comunicação entre eles e os alunos. Relataram ainda o pouco tempo disponível para a preparação prévia das aulas e a falta de materiais pedagógicos adequados.

Três afirmaram não ter o apoio de um intérprete de Libras, nem a redução do número de alunos na sala.

[...] Em muitas unidades de ensino regulares, alunos surdos ainda estudam sem intérpretes, o que revolta integrantes da Federação Nacional de Educação e Integração dos Surdos (Feneis). "A inclusão não está funcionando", diz o diretor da entidade em São Paulo, Neivaldo Augusto Zovico. "Os professores estão despreparados e as secretarias de Educação não contratam intérpretes. Os alunos acabam frustrados por não entender nada e desistem" [...].4

\footnotetext{
${ }^{4}$ Fonte: http://revistaescola.abril.com.br/inclusao/educacao-especial/falta-interpretes-fazem-inclusaoalunos-surdos-602195.shtml. Acesso em 10 de maio de 2013.
} 
Um professor relatou a falta de um programa de formação continuada para os docentes na área. A quase totalidade dos professores (quatro), dizem não existir apoio ou troca de informação com outros profissionais especializados (médico, psicólogo, fonoaudiólogo, assistente social).

Oliveira e Omote (2011) consideram, neste sentido, que existe uma urgência do campo pedagógico em buscar respostas médicas para a dificuldade de desenvolvimento escolar dos alunos com deficiência. Para os autores, é necessário outro enfoque educacional, no qual mesmo que seja necessário o uso de recursos médicos, métodos e técnicas específicas, o importante é possibilitar o avanço do alunos e a apropriação de novas formas de conhecimento.

O tempo para planejar e discutir novas estratégias é essencial. As queixas em relação ao pouco tempo para preparação prévia das aulas e falta de programa de formação continuada docente na área demonstram isso.

Um grande passo na direção de uma escola humanizadora é estabelecer uma prática dialógica. Considerando-se ser no cotidiano que se formam as representações sociais, alunos e professores precisariam ser ouvidos em suas concepções, sobre o que pensam do processo educacional, sobre suas vidas na escola e sobre a escola. Serem levados à reflexão, terem espaços de discussão de diálogo, de enfrentamento das dificuldades.

O pensar sobre o fazer pedagógico, leva a escola a refletir sobre o seu verdadeiro papel, que é levar a criança ao desenvolvimento, por maiores que sejam as suas dificuldades. Não significa desconsiderar especificidades próprias de algumas condições incapacitadoras, que interferem no curso do desenvolvimento, mas atentar também para as qualidades próprias dessas e de todas as crianças. Deixar de lado a visão homogeneizante da educação, e considerar de uma vez por todas, que a escola é lugar de diversidade. 


\section{CONSIDERAÇÕES FINAIS}

Toda esta abordagem teórica traz implicações importantes para o trabalho docente com alunos com deficiência auditiva/surdez. O surdo na maioria das vezes tem uma deficiência não aparente. Ele pode copiar, reproduzir sem entender de fato o conteúdo que está sendo aplicado. O impasse está centrado em uma questão primordial, a escola não domina a LIBRAS (Língua Brasileira de Sinais) e o surdo não domina a linguagem oral, portanto é oferecido um ambiente comunicativo inferior. Vygotsky (1999) afirma que a linguagem é o próprio pensamento. Sem a língua não se chega ao conceito abstrato, e nem tampouco à aprendizagem escolar.

É tarefa governamental oferecer total suporte para que a escola possa, de fato, incluir esse aluno, principalmente na capacitação dos professores, intérprete de LIBRAS na sala regular, adequação curricular, diminuição de alunos em sala de aula, fornecimento de materiais pedagógicos e tecnológicos específicos. A escola cabe o reconhecimento do sujeito surdo como participante ativo do seu processo educativo, entendendo a linguagem como instrumento de comunicação e expressão do pensamento. Oferecer um ambiente estimulante e proporcionar condições de troca simbólica com o meio, ou seja, uma educação para o pensar.

A família desse aluno deve ser acolhida pela escola e em parceria decidir a melhor conduta a ser tomada, tanto no aspecto social, quanto no pedagógico.

A tarefa pedagógica de desenvolvimento desses alunos exige uma ação planificada, planejada, que não se limite à transmissão do conhecimento, embora isto também seja importante, mas que seja favorecedora do desenvolvimento de nossos alunos e de suas capacidades, sejam elas quais forem.

Cabe a pedagogia que cabe este papel no cotidiano das escolas, através de práticas pedagógicas significativas, que permitam aos alunos saírem do estado de alienação e submissão, para um estado de autonomia e independência.

Concluímos, portanto, ressaltando a imensa aprendizagem e contribuição desse estudo para a formação docente do grupo. Através dele podemos entender que todas as crianças devem aprender juntas, sem distinção. A escola e os professores devem ser protagonistas no processo de inclusão escolar. O simples acesso e a garantia de matrícula na escola regular não são suficientes. 
É necessário reconhecer as necessidades dos alunos, respeitando as diferenças individuais, ou seja, não podemos ensinar a todos como se fosse um, é assim que acontece o ensino da diversidade.

Ainda vivemos um momento de superação de estigmas. Há alguns anos, era inconcebível que uma criança com deficiência auditiva frequentasse a escola. $\mathrm{Na}$ atualidade, ela tem este direito garantido, mas ainda continua à margem do conhecimento na medida em que não têm acesso aos meios e suportes que Ihes garantam realmente a aprendizagem. Por isso, conhecer de perto esta realidade nos proporcionou conhecer os problemas, mas também nos levou de encontro às possibilidades que a educação inclusiva pode trazer. Uma nova prática pedagógica, vista como um suporte necessário para a aprendizagem e como um recurso para todo e qualquer aluno que de seus serviços necessitarem, seja ele deficiente ou não. Que traz consigo um novo tempo: o tempo de possibilidades.

\section{REFERÊNCIAS BIBLIOGRÁFICAS}

BRASIL, Lei de Diretrizes e Base de 1961 - Lei 4024/61 | Lei no 4.024, de 20 de dezembro de 1961.

BRASIL. Diretrizes e Bases da Educação Nacional: nova LDB (Lei ํo 9394) Rio de Janeiro: Qualitymark Ed., 1997.

BRASIL. Resolução CNE/CEB no 2, de 11 de setembro de 2001.

BRASIL. Lei Federal 10.436, de 24 de abril de 2002 (BRASIL, 2002), reconhece a Língua Brasileira de Sinais (LIBRAS) 2002.

BRASIL. Ministério da Educação. Secretária de Educação Especial. Ensino de língua portuguesa para surdos: caminhos para a prática pedagógica / Heloísa Maria Moreira Lima Salles [et al.]. Brasília : MEC, SEESP, 2004.

BRASIL. Decreto 5.626 de 22 de dezembro de 2005.

BUSCAGLIA, L.F. Os Deficientes e seus Pais. Trad. Raquel Mendes. $5^{\mathrm{a}}$ ed. Rio de Janeiro: Record, 2006.

CAPOVILLA, F. O implante coclear como ferramenta de desenvolvimento linguístico da criança surda. Rev. Bras. Cresc. Des. Hum. São Paulo, $8^{\underline{a}}$ ed, 1998. 


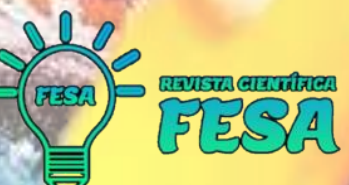

CAPOVILLA, F. C. et al. Quando alunos surdos escolhem palavras escritas para nomear figuras: paralexias ortográficas, semânticas e quirêmicas. Rev. bras. educ. espec., Marília, v. 12, n. 2, Agosto, 2006.

CAPOVILLA, F. C et al. Processos logográficos, alfabéticos e lexicais na leitura silenciosa por surdos e ouvintes. Estud. psicol. (Natal), Natal, v. 10, n. 1, Abril, 2005.

GOLDFELD, M. A criança surda: linguagem e cognição numa perspectiva socio-interacionista. $2^{\underline{a}}$ edição. São Paulo: Plexus Editora, 2002.

MEC - Ministério da Educação. Secretaria de Educação Especial - Secretaria de Educação Básica. Parâmetros curriculares nacionais: adaptações curriculares, 1998.

OLIVEIRA, A. A. S. Um diálogo esquecido: A vez e a voz de adolescentes com deficiência- Londrina: Práxis; Bauru: Canal 6, 2007

OLIVEIRA, OMOTE (org.), Inclusão Escolar: As contribuições da Educação Especial, Cultural Acadêmica, Marília, 2011.

OMS. Relatório mundial sobre a deficiência / World Health Organization, The World Bank; tradução Lexicus Serviços Linguísticos. - São Paulo: SEDPcD, 2012.

POKER, R. B. Troca simbólica e desenvolvimento cognitivo em crianças surdas: uma proposta de intervenção educacional. Tese de doutorado. UNESP - Marília, 2002.

POKER, R.B. Adequações Curriculares na área da surdez. Inclusão Escolar: as contribuições da Educação Especial. Capítulo 10. São Paulo: Cultura Acadêmica Editora e Fundepe Editora, 2008.

POKER, R.B. Abordagens Educacionais e formas de atuação com o aluno surdo. Inclusão Escolar: as contribuições da Educação Especial. Capítulo 11. São Paulo: Cultura Acadêmica Editora e Fundepe Editora, 2008.

RIZZINI, I. O século perdido: raízes históricas das políticas públicas para infância no Brasil. São Paulo: Cortez, 2008.

SACKS, Oliver, Vendo vozes: uma jornada pelo mundo dos surdos. Rio Janeiro:Imago, 1998. 


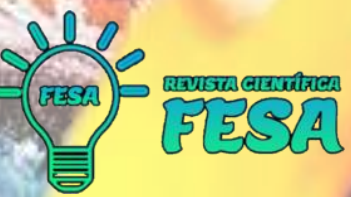

SAWREY, J.M.; TELFORD, C.W. O indivíduo excepcional. Rio de Janeiro: Zahar, 1998.

SÃO PAULO (SP). Portaria no 5.707 de 13 de dezembro de 2011. Regulamenta o decreto 52.785 de 10/10/11 que criou as escolas de educação bilíngue para surdos - Emebs na rede municipal de ensino e dá outras providências, 2011.

SÃO PAULO (SP). Secretaria Municipal de Educação. Diretoria de Orientação Técnica. Orientações curriculares e proposição de expectativas de aprendizagem para Educação Infantil e Ensino Fundamental: Libras / Secretaria Municipal de Educação - São Paulo: SME / DOT, 2008.

SOUZA, S.M. Apontamentos sobre a formação de professores bilíngues para educação de surdos em língua de sinais. Campinas, SP: [s.n.], 2012.

VYGOTSKY, L. S. A formação social da mente - o desenvolvimento dos processos psicológicos superiores. São Paulo: Martins Fontes, 6ª̉ed., 1998.

VYGOTSKY, L. S. Pensamento e Linguagem. São Paulo: Martins Fontes, 2 ed., 1999. 